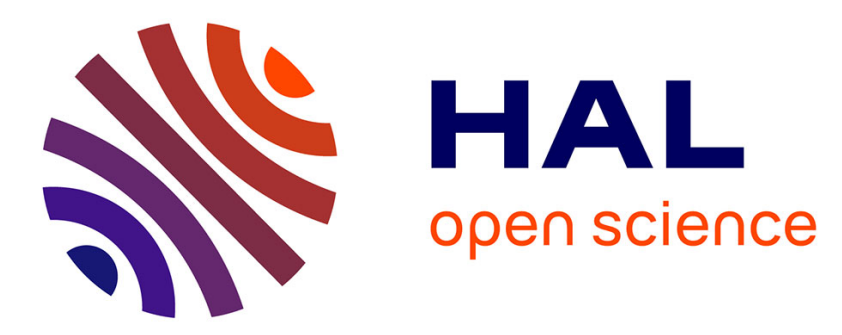

\title{
Tick-borne pathogens in removed ticks Veneto, northeastern Italy: A cross-sectional investigation
}

Anna Beltrame, Maureen Laroche, Monica Degani, Francesca Perandin, Zeno Bisoffi, Didier Raoult, Philippe Parola

\section{- To cite this version:}

Anna Beltrame, Maureen Laroche, Monica Degani, Francesca Perandin, Zeno Bisoffi, et al.. Tickborne pathogens in removed ticks Veneto, northeastern Italy: A cross-sectional investigation. Travel Medicine and Infectious Disease, 2018, 26, pp.58-61. 10.1016/j.tmaid.2018.08.008 . hal-01970220

\section{HAL Id: hal-01970220 \\ https://hal.science/hal-01970220}

Submitted on 10 Apr 2019

HAL is a multi-disciplinary open access archive for the deposit and dissemination of scientific research documents, whether they are published or not. The documents may come from teaching and research institutions in France or abroad, or from public or private research centers.
L'archive ouverte pluridisciplinaire HAL, est destinée au dépôt et à la diffusion de documents scientifiques de niveau recherche, publiés ou non, émanant des établissements d'enseignement et de recherche français ou étrangers, des laboratoires publics ou privés. 


\title{
Tick-borne pathogens in removed ticks Veneto, northeastern Italy: A cross- sectional investigation
}

\author{
Anna Beltrame $e^{\mathrm{a}, *}$, Maureen Laroche ${ }^{\mathrm{b}}$, Monica Degani ${ }^{\mathrm{a}}$, Francesca Perandin ${ }^{\mathrm{a}}$, Zeno Bisoffi ${ }^{\mathrm{a}}$, \\ Didier Raoult ${ }^{\mathrm{c}}$, Philippe Parola ${ }^{\mathrm{b}}$ \\ ${ }^{\text {a }}$ Centre for Tropical Diseases, IRCCS Sacro Cuore Don Calabria Hospital, Via Sempreboni 5, 37024, Negrar, Italy \\ ${ }^{\mathrm{b}}$ Aix Marseille Univ, AP-HM, SSA, VITROME, IHU-Méditerranée Infection, 19-21 Bd Jean Moulin, 13005, Marseille, France \\ ' Aix Marseille Univ, AP-HM, MEPHI, IHU-Méditerranée Infection, 19-21 Bd Jean Moulin, 13005, Marseille, France
}

\section{A R T I C L E I N F O}

\section{Keywords:}

Tick-borne diseases

Ticks

Borrelia

Rickettsia

Anaplasma

Italy

\begin{abstract}
A B S T R A C T
Background: In Italy, the incidence of tick-borne diseases in humans is underestimated, as they are not obligatorily notifiable. The aim of this study was to investigate the presence of tick-borne pathogens in ticks removed from human subjects in Veneto region (northeastern Italy), an area for which no published studies are yet available.

Method: Forty-five ticks prospectively removed from human subjects, between March and August 2016, were analysed for bacterial DNA.

Results: Seven of 45 ticks were infected with bacteria, including human pathogens: 4 Rickettsia spp. (9\%), including $R$. monacensis and $R$. helvetica; 3 Borrelia spp. and 1 Anaplasma phagocytophilum. Three subjects bitten by infected ticks reported symptoms.

Conclusions: Rickettsiosis and anaplasmosis, tick-borne diseases previously not considered in northeastern Italy, should not be neglected. A new survey for a longer period is required to obtain stronger epidemiological data.
\end{abstract}

\section{Introduction}

In Europe, the incidence of human tick-borne diseases (TBD) is increasing [1]. In Italy, the incidence of TBD in humans is underestimated, as they are not obligatorily notifiable. Most cases of lyme borreliosis (LB) [2] and tick-borne encephalitis (TBE) [3] occur in northern Italy (frequently in Friuli-Venezia-Giulia, Trentino Alto Adige, Veneto), whereas Mediterranean spotted fever caused by Rickettsia conorii [4] is observed prevalently in central and southern Italy (mostly in Sicily). Other rickettsial infections are rarely reported and so are anaplasmosis and babesiosis [5-7]. However, in all probability, many of these recently emerging TBD are unrecognized [1]. Moreover, the diagnostic tests are not widely available.

Numerous tick ecology studies carried out in northern Italy on flagging vegetation or animals indicate the presence of various tickborne pathogens, prevalent in Ixodes ricinus ticks that is the most common vector: Borrelia burgdorferi s.l., and other emerging pathogens such as Anaplasma phagocytophilum, Babesia spp. and Rickettsia spp
[8-12]. In particular, the Rickettsia species isolated in ticks from alpine and pre-alpine northern areas have been $R$. helvetica and $R$. monacensis [10-12] differently from southern areas (i.e. Sardinia) where in addition to $R$. helvetica, have been detected also $R$. hoogstraalii, $R$. massiliae, $R$. slovaca and $R$. aeschlimannii [13].

The identification of tick-borne pathogens from ticks removed from people is a good strategy for monitoring the circulation of TBD in a specific area [1,14]. This entomologic study, compared to standard tick dragging whose results only concern the monitored areas, permits to describe the pathogen circulation both in traditional risk areas (woodland) and in areas located near human dwellings (e.g. gardens and urban parks) where tick sampling is not normally carried out.

The aim of this study was to investigate the presence of tick-borne bacteria and parasites in Veneto region (northeastern Italy), an area for which no published studies are yet available, on ticks removed from human subjects.

\footnotetext{
Abbreviations: TBD, Tick-borne Diseases; LB, Lyme borreliosis; TBE, tick-borne encephalitis; ER, Emergency Room; qPCR, quantitative real-time PCR

* Corresponding author. Centre for Tropical Diseases, Sacro Cuore Don Calabria Hospital, Via Sempreboni 5, 37024, Negrar, Italy.

E-mail addresses: anna.beltrame@sacrocuore.it (A. Beltrame), maureen.laroche972@gmail.com (M. Laroche), monica.degani@sacrocuore.it (M. Degani), francesca.perandin@sacrocuore.it (F. Perandin), zeno.bisoffi@sacrocuore.it (Z. Bisoffi), didier.raoult@gmail.com (D. Raoult), philippe.parola@univ-amu.fr (P. Parola).
} 


\section{Material and methods}

Between March 10, 2016 and August 1, 2016 ticks were prospectively collected at the Emergency Room (ER) of Sacro Cuore Don Calabria Hospital of Negrar (Verona) $\left(45^{\circ} 32^{\prime} \mathrm{N}, 10^{\circ} 56^{\prime} \mathrm{E}\right)$. The ticks had been removed either by the subjects themselves or subsequently by the doctors.

People were asked for an informed consent to collect a questionnaire and for testing the ticks. Post-bite prophylaxis was not prescribed in line with current recommendations [15]. The subjects were advised to perform the serology for $B$. burgdorferi by enzyme-linked immunosorbent assay 6-8 weeks after the tick extraction.

Ticks were subjected to morphological identification and molecular detection of pathogens at the reference centre for rickettsioses, IHUMéditerranée Infection, Marseille, France.

Tick DNA was individually extracted using the DNA extracting EZ1 Advanced XL Robot (Qiagen) along with its EZ1 DNA tissue extraction kit according to the manufacturer's instructions. DNA samples were individually tested by genus-specific quantitative real-time PCR (qPCR) using primers and probes targeting bacterial specific sequences of Rickettsia spp. (gltA), Bartonella spp. (ITS2), Borrelia spp. (ITS4), Coxiella burnetii (IS30A) and Anaplasmataceae bacteria (23S) as previously described [16]. Protozoa including Babesia spp. and Theileria spp. were also screened by qPCR targeting fragments of the $18 \mathrm{~S}$ and $28 \mathrm{~s}$ genes respectively [17]. Bartonella elizabethae, Rickettsia montanensis, C. burnetii, A. phagocytophilum and Borrelia crocidurae DNAs were used as positive $\mathrm{qPCR}$ controls for the primers and probe targeting respectively Bartonella spp., Rickettsia spp., C. burnetii, Anaplasmataceae spp. and all Borrelia species. DNA samples that were positive in qPCR were submitted to conventional PCR amplification prior to sequencing as previously described [14]. The sequences obtained were compared to sequences available in the GenBank database using the BLAST algorithm as described [14].

\section{Results}

The 45 participants ( 23 men and 22 women) had a median age of 22.8 years (range $1-74$ years). Children $\leq 10$ years old accounted for $29 \%$ of them.

Tick bites occurred outside Veneto were reported by seven subjects (Table 1). Of the latter, only one patient reported a short travel outside Italy (Croatia) and found the tick soon after return. The tick bites occurred during recreational activities in rural and periurban habitats: 44 (98\%) during leisure activities, 7 (16\%) during outdoor activities in the geographic area of residency, while the remaining during weekend activities in other areas. The participants at the moment of the visit reported between one to three tick bites. Four subjects reported tick-

Table 1

Detection of bacteria in ticks removed from people, Italy.

\begin{tabular}{|c|c|c|c|c|c|c|}
\hline \multirow[b]{3}{*}{ Ticks } & \multirow{2}{*}{$\begin{array}{l}\text { Region } \\
\text { Province }\end{array}$} & \multicolumn{2}{|l|}{ Veneto } & \multirow{2}{*}{$\begin{array}{l}\text { Trentino } \\
\text { Alto Adige } \\
\text { Trento }\end{array}$} & \multirow{2}{*}{$\begin{array}{l}\text { Friuli } \\
\text { Venezia } \\
\text { Giulia }\end{array}$} & \multirow{2}{*}{$\begin{array}{l}\text { Other } \\
\text { (Puglia } \\
\text { Marche } \\
\text {-Croatia) }\end{array}$} \\
\hline & & Verona & Belluno & & & \\
\hline & $\mathrm{N}=45$ & $\mathrm{n}=37$ & $\mathrm{n}=1$ & $\mathrm{n}=3$ & $\mathrm{n}=1$ & $\mathrm{n}=3$ \\
\hline Bacteria & $\begin{array}{l}\text { positive } \\
\mathrm{n}(\%)\end{array}$ & $\begin{array}{l}\text { positive } \\
\mathrm{n}(\%)\end{array}$ & $\begin{array}{l}\text { positive } \\
\mathrm{n}(\%)\end{array}$ & $\begin{array}{l}\text { positive } \\
\mathrm{n}(\%)\end{array}$ & $\begin{array}{l}\text { positive } \\
\mathrm{n}(\%)\end{array}$ & $\begin{array}{l}\text { positive } \\
\mathrm{n}(\%)\end{array}$ \\
\hline $\begin{array}{c}\text { Rickettsia } \\
\text { spp. }\end{array}$ & $4(9)$ & $3(8.1)$ & - & - & $1(100)$ & - \\
\hline Borrelia spp. & $3(7)$ & $2(5.4)$ & - & $1(33.3)$ & - & - \\
\hline $\begin{array}{c}\text { Anaplasma } \\
\text { spp. }\end{array}$ & $1(2)$ & $1(2.7)$ & - & - & - & - \\
\hline $\begin{array}{l}\text { Total ticks } \\
\text { positive }\end{array}$ & 7 (15.5) & $6(16.2)$ & - & $1(33.3)$ & $1(100)$ & - \\
\hline
\end{tabular}

bites in more than one body area.

Overall, 45 ticks were collected. Forty-three (96\%) ticks were identified as I. ricinus and $2(4 \%)$ as $R$. sanguineus s.l. Of these ticks, 26 (58\%) were adults, 15 (33\%) were nymphs and 4 (9\%) were larvae.

Seven ticks (16\%), all I. ricinus, were infected with at least one microorganism (Table 1). The most frequent were Rickettsia spp., with an overall prevalence of $9 \%(4 / 45)$.

Using a standard PCR and sequencing, we identified one $R$. monacensis and one $R$. helvetica in $2 I$. ricinus, while the two other Rickettsia species detected in qPCR were not successfully sequenced. The second most frequent identified microorganisms were Borrelia spp., with a prevalence of $7 \%$ (3/45). Sequencing did not allow identification of this Borrelia sp. to the species level. Anaplasma phagocytophilum was found in one tick (2\%). Co-infection was detected in one tick harbouring Borrelia spp. and $R$. helvetica.

The ticks removed from people exposed in Veneto region (in particular, the province of Verona) were infected by Rickettsia spp. (3/38, 7.9\%), Borrelia spp. (2/38, 5.3\%) and Anaplasma (1/38, 2.6\%) (Fig. 1).

Participants had removed the infected ticks in a mean of 1.2 days (range 1-3 days). They were interviewed by phone on symptoms and signs eventually occurring up to three months after the tick bite. Three (43\%) subjects bitten by an infected tick reported symptoms within the first two weeks (mean 7.3 days, range 2-14 days).

A 23-year-old man reported the appearance of a rash, compatible with early localized LB, five days after the bite of the tick infected with Borrelia spp. He was successful treated with doxycycline. A 73-year-old woman reported neck-pain and mild gastro-intestinal symptoms (nausea and abdominal pain) six days after the bite of the tick co-infected with Borrelia spp. and $R$. helvetica. She reported a negative result of serology for Borrelia and spontaneous healing of the symptoms in few days without any treatment. Finally, an 8-year-old child reported right monolateral coxo-femoral pain 14 days after a tick-bite. The tick carried A. phagocytophilum. No serology was performed and the patient recovered without treatment.

\section{Discussion}

In Veneto Region, where nearly 800 cases of LB were reported during 2006-2017 (regional registry), no human autochthonous cases of other TBD, excluding TBE, have been ever reported.

Our study is one of the few on ticks removed from people [14]. In addition to LB, rickettsiae are also of concern, being the most prevalent TB microorganisms found in the ticks collected from humans in this area. In particular, in Veneto we found $R$. monacensis and $R$. helvetica, which are known to be emergent pathogens associated to I. ricinus [10-12] and classified as human pathogen species [7,13]. These tickborne pathogens had already been identified in previous studies conducted in other provinces of Veneto collecting ticks by dragging $[9,10]$. Of 1931 ticks collected within the territory of Belluno during the period 2000-2001, 305 (15.8\%) resulted positive: 8\% B. burgdorferi, 4.4\% A. phagocytophilum, 1.6\% Rickettsia spp. and Babesia spp., respectively [9]. Capelli et al., from 2006 to 2008 collected 86 ticks from other sites in provinces of Veneto [10]. Thirty-four (39.5\%) resulted infected with at least one pathogen: $15 \% R$. helvetica, 14\% Borrelia spp. and $1.2 \%$ A. phagocytophilum. According to recent guidelines focuses on Lyme borreliosis, the use of single-oral-dose doxicicline for tick-bite prophylaxis is not recommended [15]. The risk of Borrelia infection after a tick bite has been shown to be low. A prospective study showed that $8 \%$ of people bitten by a $B$. burgdorferi infected tick acquired the infection [18]. However, it is well known that the risk steadily rises with the increasing duration of the blood meal, reaching $70 \%$ if the tick remains attached up to $72 \mathrm{~h} \mathrm{[19].}$

Most of our study subjects removed the infected ticks soon after the bite, which probably reduced the risk of transmission of Borrelia. In the patient with a diagnosis of early localized LB, the tick was removed three days after a risk exposure. In contrast, the patient bitten by a 


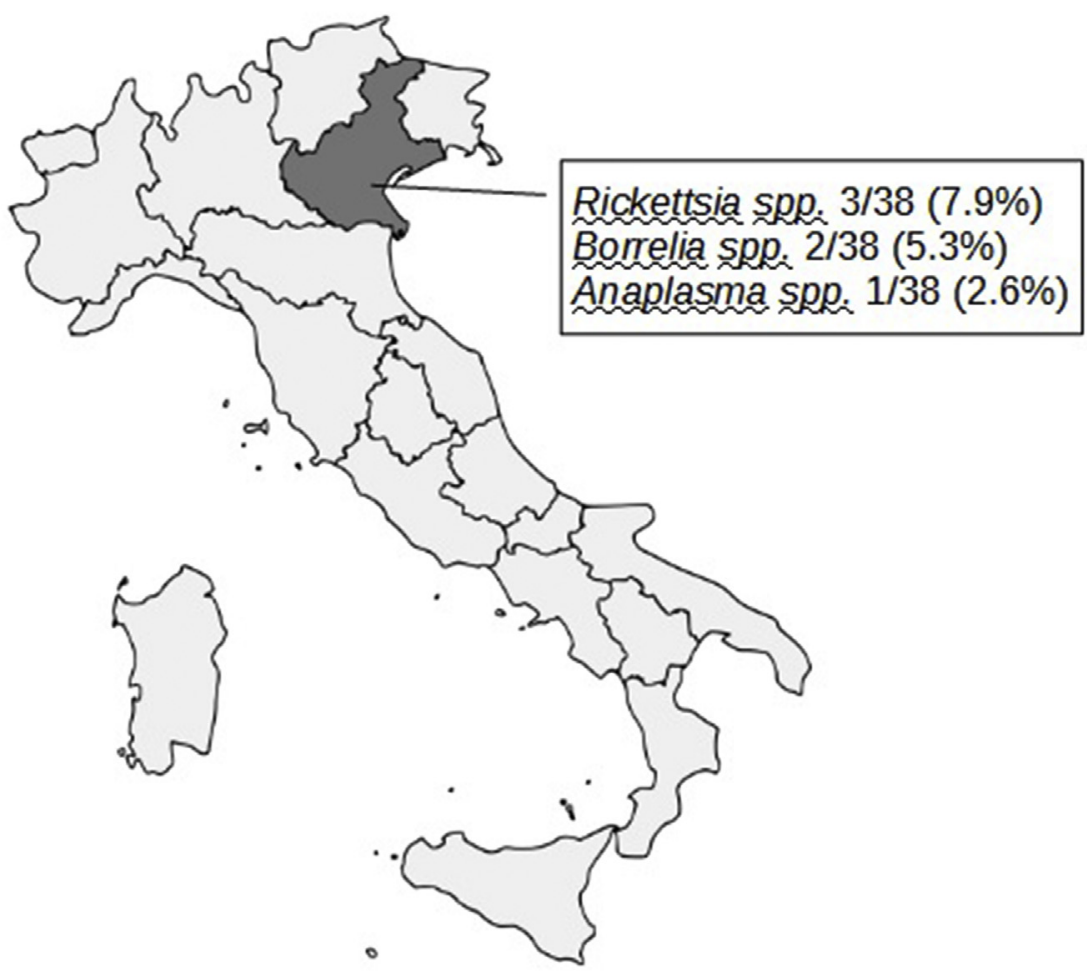

Fig. 1. Number of tick-borne pathogens in removed ticks from people exposed in Veneto region, northeastern Italy.

Borrelia spp. and R. elvetica co-infected tick, althoughthe latter was removed within the first $24 \mathrm{~h}$, developed symptoms probably correlated to $R$. helvetica infection as the serology for Borrelia remained negative. In fact, the blood feeding time required for transmission of rickettsia to the host is shorter than Borrelia, ranging from $10 \mathrm{~min}$ to $10 \mathrm{~h} \mathrm{[20].}$ Unfortunately, a serology for rickettiosis was not available. Finally, the third symptomatic patient was bitten by a tick infected by A. phagocytophilum, which can be transmitted after $24 \mathrm{~h}$ of tick attachment. However, in this case a specific serology was not available, either.

The most effective strategy to prevent a TBD remains to avoid tick bites by wearing protective clothing or using repellents during a stay in a risk area. Moreover, the skin and head (particularly of young children) should be carefully checked after outdoors activities to permit an immediate removal of an attached tick.

\section{Conclusion}

Besides the most known diseases, LB and TBE, rickettsiosis and anaplasmosis, previously not considered in northeastern Italy, should not be neglected. A new prospective survey for a longer period is in necessary to obtain bigger sample size and strengthen these results.

\section{Declaration of interest}

The authors declare that they have no any actual or potential conflict of interest including any financial, personal or other relationships with other people or organization within three years of beginning the submitted work that could inappropriately influence, or be perceived to influence, their work.

\section{Funding}

This research did not receive any specific grant from funding agencies in the public, commercial, or not-for-profit sectors.

\section{Acknowledgements}

The authors thank Stefano Tais for technical support and Manuela Mistretta for assistance with tick identification.

\section{References}

[1] Hai VV, Almeras L, Socolovschi C, Raoult D, Parola P, Pages F. Monitoring human tick-borne disease risk and tick bite exposure in Europe: available tools and promising future methods. Ticks and tick-borne diseases 2014;5(6):607-19.

[2] Esposito S, Baggi E, Villani A, et al. Management of paediatric lyme disease in nonendemic and endemic areas: data from the registry of the Italian society for pediatric infectious diseases. Eur J Clin Microbiol Infect Dis 2013;32(4):523-9. official publication of the European Society of Clinical Microbiology.

[3] Rezza G, Farchi F, Pezzotti P, et al. Tick-borne encephalitis in north-east Italy: a 14 year retrospective study, January 2000 to December 2013. Euro Surveill 2015;20(40). bulletin Europeen sur les maladies transmissibles = European communicable disease bulletin.

[4] Vitaliti G, Falsaperla R, Lubrano R, et al. Incidence of Mediterranean spotted fever in Sicilian children: a clinical-epidemiological observational retrospective study from 1987 to 2010. Int J Infect Dis: Int J Infect Dis 2015;31:35-40. official publication of the International Society for Infectious Diseases.

[5] Piccaluga PP, Poletti G, Martinelli G, Gherlinzoni F. Babesia infection in Italy. Lancet Infect Dis 2004;4(4):212.

[6] Beltrame A, Ruscio M, Arzese A, et al. Human granulocytic anaplasmosis in northeastern Italy. Ann N Y Acad Sci 2006;1078:106-9.

[7] Madeddu G, Mancini F, Caddeo A, et al. Rickettsia monacensis as cause of Mediterranean spotted fever-like illness. Italy. Emerging infectious diseases 2012;18(4):702-4.

[8] Mantelli B, Pecchioli E, Hauffe HC, Rosa R, Rizzoli A. Prevalence of Borrelia burgdorferi s.l. and Anaplasma phagocytophilum in the wood tick Ixodes ricinus in the Province of Trento, Italy. Eur J Clin Microbiol Infect Dis 2006;25(11):737-9. official publication of the European Society of Clinical Microbiology.

[9] Piccolin G, Benedetti G, Doglioni C, et al. A study of the presence of B. burgdorferi, Anaplasma (previously Ehrlichia) phagocytophilum, Rickettsia, and Babesia in Ixodes ricinus collected within the territory of Belluno. Italy. Vector borne and zoonotic diseases 2006;6(1):24-31.

[10] Capelli G, Ravagnan S, Montarsi F, et al. Occurrence and identification of risk areas of Ixodes ricinus-borne pathogens: a cost-effectiveness analysis in north-eastern Italy. Parasites Vectors 2012;5:61.

[11] Corrain R, Drigo M, Fenati M, et al. Study on ticks and tick-borne zoonoses in public parks in Italy. Zoonoses and public health 2012;59(7):468-76.

[12] Otranto D, Dantas-Torres F, Giannelli A, et al. Ticks infesting humans in Italy and associated pathogens. Parasites Vectors 2014;7:328.

[13] Chisu V, Leulmi H, Masala G, Piredda M, Foxi C, Parola P. Detection of Rickettsia 
hoogstraalii, Rickettsia helvetica, Rickettsia massiliae, Rickettsia slovaca and Rickettsia aeschlimannii in ticks from Sardinia, Italy. Ticks and tick-borne diseases 2017;8(3):347-52

[14] Aubry C, Socolovschi C, Raoult D, Parola P. Bacterial agents in 248 ticks removed from people from 2002 to 2013. Ticks and tick-borne diseases 2016;7(3):475-81.

[15] Hofmann H, Fingerle V, Hunfeld KP, et al. Cutaneous lyme borreliosis: guideline of the German dermatology society. German medical science. GMS e-journal 2017;15. Doc14.

[16] Diarra AZ, Almeras L, Laroche M, et al. Molecular and MALDI-TOF identification of ticks and tick-associated bacteria in Mali. PLoS Neglected Trop Dis 2017;11(7):e0005762

[17] Aouadi A, Leulmi H, Boucheikhchoukh M, Benakhla A, Raoult D, Parola P.
Molecular evidence of tick-borne hemoprotozoan-parasites (Theileria ovis and Babesia ovis) and bacteria in ticks and blood from small ruminants in Northern Algeria. Comp Immunol Microbiol Infect Dis 2017;50:34-9.

[18] Wilhelmsson P, Fryland L, Lindblom P, et al. A prospective study on the incidence of Borrelia burgdorferi sensu lato infection after a tick bite in Sweden and on the Aland Islands, Finland (2008-2009). Ticks and tick-borne diseases 2016;7(1):71-9.

[19] Eisen L. Pathogen transmission in relation to duration of attachment by Ixodes scapularis ticks. Ticks and tick-borne diseases 2018;9(3):535-42.

[20] Saraiva DG, Soares HS, Soares JF, Labruna MB. Feeding period required by Amblyomma aureolatum ticks for transmission of Rickettsia rickettsii to vertebrate hosts. Emerg Infect Dis 2014;20(9):1504-10. 